\title{
Agronegócio e reforma agrária: discursos, símbolos e os elementos de análise na relação política
}

\author{
Agribusiness and land reform: discourses, symbols, and the elements of analysis in the political \\ relations
}

\author{
Cássia Morgana Faxina Pacheco ${ }^{1}$ \\ Hilda Alberton de Carvalho
}

\begin{abstract}
Resumo
Este trabalho objetiva uma reflexão sobre a separação em dois tipos de agricultura que se formaram no Brasil e entender suas origens e a razão de serem colocadas como antagônicas. Considerando os constantes e perpétuos ataques à política pública de reforma agrária, este trabalho fará uma Análise do Discurso da Frente Parlamentar Agropecuária (FPA) a fim de se aprofundar na narrativa que tem sido formatada desde a redemocratização do país e provocar reflexões sobre esse discurso nos últimos anos. Conclui-se que essa disputa tem implicação direta na destinação do fundo público e no modelo de Estado que cada um desses grupos almeja.
\end{abstract}

Palavras-chave: Análise de Discurso. Reforma Agrária. Agronegócio. Política pública.

\begin{abstract}
This paper aims at a reflection on the distinction between two types of agriculture raised in Brazil, to understand their origins and the reason for being considered antagonist. In the face of the constant and perpetual attacks against the public policy of land reform, the paper analyzes the Discourse of the Parliamentary Front of Agriculture (FPA). The objectives are to deepen the narrative formatted since the country's re-democratization and to foster reflections on this discourse in the last years. We conclude that this dispute implies directly in the public fund destination as well as in the state models that these groups aim for.
\end{abstract}

Keywords: Discourse Analysis. Land reform. Agribusiness. Public policy.

\section{Introdução}

Estudos realizados sobre o tema da reforma agrária têm provado que a implantação dos assentamentos rurais vem alterando a geografia agrária do país. A criação de um assentamento na região traz consigo a chegada dos créditos de instalação, dos recursos para infraestrutura, o desenvolvimento da produção e seus efeitos sobre o emprego e o comércio local que repercutem sobre a economia regional (LEITE et al., 2004). Nessa direção, os assentamentos criados pelo governo a partir de 2004 passaram a ter como orientação o desenvolvimento territorial e a viabilidade econômica e sustentabilidade ambiental. (BRASIL, 2003).

\footnotetext{
${ }^{1}$ Instituto Nacional de Colonização e Reforma Agrária no Paraná. E-mail: cassia.faxina@gmail.com

${ }^{2}$ Universidade Tecnológica Federal do Paraná. E-mail: hilda@utfpr.edu.br
} 
Em contrapartida, os momentos políticos mais recentes acabaram por restringir o orçamento da autarquia responsável pelo assentamento de famílias - o Instituto Nacional de Colonização e Reforma Agrária (Incra) - e consequentemente mudou-se o direcionamento da política pública de reforma agrária. A argumentação para a nulificação desta política pública é que com o progresso da agricultura extensiva, a renda de milhares de produtores de pequeno porte não é relevante para sustentar o "dinamismo do mercado interno", além de colaborar quase que irrelevantemente com a produção de alimentos. Sendo a evolução tecnológica e a intensificação de produção as maiores responsáveis pela oferta de alimentos e não a redistribuição de terras e o fomento da agricultura familiar (BUAINAIN et al, 2013, p.115).

Verifica-se, desta forma, que há um enfrentamento discursivo e simbólico contrário à implantação e manutenção das políticas públicas de fomento à agricultura familiar e de reforma agrária. Tal antagonismo culmina em determinado momento histórico brasileiro na existência de dois Ministérios voltados, cada um, para o seu público demandante: o Ministério da Agricultura, Pecuária e Abastecimento (MAPA) e o Ministério do Desenvolvimento Agrário (MDA). Ambos dividiram pastas e espaço na esplanada dos ministérios entre os anos de 1999 e - ano de criação do MDA até sua extinção - 2016. Os investimentos nesses ministérios não carregavam uma relação de proporcionalidade com o quantitativo de pessoas beneficiadas por eles. Em um resgate histórico dos censos agropecuários (IBGE, 2007) é verificado a quantidade de pessoas ocupadas em estabelecimentos agropecuários familiares sempre é superior a $70 \%$ do contingente de pessoas ocupadas no campo, quando comparado os dados do orçamento de cada ministério, observa-se que o MDA não chegou à metade dos investimentos destinados ao MAPA.

Portanto, não apenas coexistiram dois ministérios cuja definição das ações se dá pela distinção de seus públicos como também seus investimentos não são proporcionais à quantidade de pessoas atendidas e ainda são organizados dois planos de safras diferenciados. Gerando assim uma noção de que existem dois modelos de agricultura em um mesmo Estado e estes grupos diferentes mantém interesse sobre o mesmo fundo público.

O Estado, tal qual sua concepção desde a antiguidade, é, resumidamente, um grupo de indivíduos que, organizados, delegam seu poder individual para esta entidade a fim de zelar e tomar decisões em nome da coletividade. São três os elementos necessários para que um Estado se forme: povo, território e soberania e, para sua organização, este estado estabelece normas escritas (AZAMBUJA, 2008). O que entendemos como Estado Brasileiro, possui em sua última e válida constituição a garantia, nos artigos 184 e seguintes, do acesso à terra a trabalhadores rurais e suas 
famílias com o objetivo de redistribuir os direitos sobre a propriedade privada agrícola a fim de promoção da justiça social e aumento da produtividade (BRASIL, 1988).

A reforma agrária, portanto, é uma política de Estado que tem como objetivo o bem coletivo (pois assim o Estado, que recebeu de forma delegativa o poder de seu povo, deve agir), a fim de atuar na base de dois de seus elementos constitutivos: a redistribuição do seu território para as pessoas do seu povo. O uso do território nacional por parte da população pode gerar riquezas particulares. A geração dessas riquezas para só uma parte da sua população (e não pelo coletivo) fez com que o Estado interviesse através de políticas de distribuição fundiária. Na concepção da Economia, a terra é considerada um bem de produção e é um meio usado para produzir bens de consumo. Sua concentração ou distribuição por parte do Estado interfere diretamente na concentração (ou distribuição) de renda e dos bens de produção. Por isso as reformas fundiárias também interferem na reversão da exclusão social e diz respeito às necessidades básicas de alimentação, geração de riquezas e moradia de seu povo.

\section{Metodologia}

Muito do que se tem instituído sobre as relações de rural e urbano, de desenvolvimento e atraso, classes sociais, moderno e ultrapassado, movimentos sociais, etc., foi construído através dos discursos que circulam socialmente. Ser sem-terra ou ruralista, assentado da reforma agrária ou grande proprietário de terras, são formas de ser que a sociedade infere através das construções discursivas, do imaginário simbólico que faz reger os contratos sociais.

O método de Análise do Discurso é um campo de estudos que se origina da linguística e da comunicação que pesquisa construções ideológicas presentes em um texto (ORLANDI, 2012). A disciplina surge nos anos de 1960 através dos trabalhos de Michel Pêcheux e sua equipe alocada na França e agrega, além dos conhecimentos provenientes do campo de estudo da linguística e da comunicação, o materialismo histórico e a psicanálise (MACHADO, 1998). Através da Análise do Discurso é possível entendermos o que o texto diz, como é dito e por que este texto diz o que ele diz. Diferentemente do seu sentido lógico e linguístico, a Análise do Discurso tem como preocupações a interpretação do texto em relação com o contexto social, histórico e político em que ele é produzido.

Neste trabalho específico, abordaremos os discursos formulados pela Frente Parlamentar da Agropecuária (FPA) em seu canal de comunicação oficial: o site fpagropecuaria.org.br. A escolha pelos textos do canal oficial de comunicação da FPA se justifica por ser um grupo responsável pela 
formulação das políticas públicas dentro do Estado. Desta forma, observa-se que a FPA - na plataforma do seu site oficial e seus canais de informações também oficiais - é um meio de comunicação que propaga a voz do agronegócio e está diretamente ligado a formulação de políticas públicas na disputa de poder dentro do Estado. O estudo dos textos da Frente nos mostrará exatamente as falas do agronegócio dentro do Estado brasileiro e qual o discurso dos formuladores de políticas públicas que contrapõe à política de reforma agrária

Para esta pesquisa, foram selecionados todos os textos publicados e com acesso liberado e divulgados pela Agência de Notícias da FPA sem data de início e limitando até a data de 01 de julho de 2019. A pesquisa foi filtrada de forma a extrair os textos que tivessem relação com a política pública de reforma agrária. Um primeiro filtro com a temática foi realizado e chegou-se a 118 textos publicados com data inicial de dezembro de 2012 até julho de 2019. Após a leitura e pré-análise, foram selecionados 48 textos em estilo jornalístico e artigos assinados que foram escritos pelos membros da FPA ou por sua assessoria de imprensa.

\section{Resultados: a imagem que a FPA tem dela mesma e da política pública de reforma agrária}

A FPA congrega das mesmas ideias e discurso do setor que representa, assim, ambos são, sob este olhar, combativos e aguerridos na luta por seus direitos. A "bancada que tem presença importante na Câmara e que teve papel fundamental no processo de impedimento da presidente Dilma" (TEMER, 2016), promove lobby em prol de suas causas e é constantemente responsável por indicação de ministro para o Ministério da Agricultura e Comissões Parlamentares de Inquéritos a fim de ampliar a influência do setor no governo. É "uma das mais atuantes no Congresso Nacional, mais de 200 deputados formam a bancada ruralista que sempre vota em peso nos pleitos que interessam ao setor produtivo rural, o mais exitoso da economia brasileira" (BANCADA, 2017).

O agronegócio brasileiro é o "esteio ou a coluna vertebral da economia brasileira" (AGROPECUÁRIA, 2015), a "galinha dos ovos de ouro" (BOTELHA, 2016). Também se vê como o setor responsável pela alimentação de forma acessível para populações urbanas no Brasil e no mundo. Todo esse aparato capitalista, moderno, produtivista e a "ideologia tecnológica no campo" seriam responsáveis por um ganho em alimentação e diminuição dos custos que "permitiram que, em 2013, cada trabalhador gastasse com a cesta básica de alimentos cerca de metade do valor, em preços reais, que gastava em meados dos anos 1970. A sorte das metrópoles que não dependeu da reforma agrária" (GRAZIANO, 2015). 
Quando o governo prioriza pautas como a reforma agrária, torna-se injusto por sua importância para o abastecimento interno e para a balança comercial (AMATO, 2012). O setor demanda de incentivo fiscal e de legislações que permitam a produção em detrimento a outras pautas e de investimento por parte do governo (AGROPECUÁRIA, 2015). Os produtores rurais estão sendo "expulsos da sua terra" para garantir a demarcação de reservas indígenas (MIRANDA e ARAÚJO, 2013); São “azucrinados” por Organizações Não Governamentais (ONG’s) ambientais, com pautas indígenas ou de movimentos sociais pois essas organizações são "inconvenientes em seus pedidos" (ONGS, 2015). Também sofrem injustiças quando as áreas destinadas a unidades de conservação, terras indígenas, comunidades quilombolas e assentamentos de reforma agrária são "quase o dobro da cultivada atualmente em grãos no Brasil, responsável por cerca de 190 milhões de toneladas na última safra" (MIRANDA, 2015). Também são protetores do meio ambiente e produzem de forma sustentável (FPA, sem data e SENADO, 2014) e, ainda assim, o governo "exige que os agricultores assumam o ônus de preservar porções significativas no interior de seus imóveis rurais, como reserva legal ou áreas de preservação permanente" (MIRANDA, 2015). São os legítimos donos das terras que ocupam (PRODUTORES, 2013; MINISTRO, 2013) e justifica-se isso a produção que mantém (TERRAS, 2015).

O discurso da FPA reflete a política pública da reforma agrária como uma política pública não efetiva, que não passaria de "discurso". Essa mesma política é "morosa" e possui "falta de controle" (NILSON, 2015). Insistir nessa política é um desperdício de dinheiro público, haja vista a dificuldade em "encontrar terras para serem desapropriadas, pois os fazendeiros aprimoraram seu nível tecnológico e elevaram sua produtividade" (GRAZIANO, 2015). Assim o Incra trabalha "ideologicamente" para atender pautas de grupos de interesse e a "sanha do distributivismo agrário" (GRAZIANO, 2015). As famílias assentadas produzem pouco ou quase nada, pois “os índices médios de produtividade dos assentamentos encontram-se abaixo dos verificados na agricultura de 1975. Sanar essa absurda fraqueza deveria ser a prioridade da reforma agrária" (GRAZIANO, 2015).

Essa política pública pode colocar em risco toda uma possível segurança alimentar da população e o próprio andamento da economia brasileira, haja vista que não a promoção da reforma agrária "pode repercutir no crescimento do preço da terra e no custo dos alimentos" (MIRANDA, 2015). A reforma agrária também aparece como uma política pública atrasada pois ela já foi realizada e não tem necessidade de continuar existindo: “O Brasil já fez a maior reforma agrária já executada em qualquer parte do mundo em qualquer tempo da história" e o que foi feito pode ter sido feito de forma errada, já que "pouco se sabe sobre os resultados da reforma agrária e sobre as condições de vida dos assentados" (EM, 2015). 
Em relação ao público ao qual a política pública se destina, afirma-se que os assentamentos são "fracassados", pois há "abandono, arrendamento e venda de lotes". Os assentamentos ainda dependem "de recursos do contribuinte", portanto a reforma agrária "torna-se inviável e é executada para o benefício exclusivo de seus aliados" (SPERAFICO, 2016). Os demandantes da política pública formam um "exército" através de movimentos sociais que agrupam "muito mais trabalhadores urbanos desempregados, que foram em grande parte absorvidos pelo mercado de trabalho em expansão e pelas transferências governamentais" (AMATO, 2012). São responsáveis por organizar e fomentar "o conflito agrário no campo, trazendo essa insegurança jurídica que presenciamos no dia a dia, ações essas de violência e desobediência civil" (ONGS, 2015). São continuamente demandantes de política pública que nunca é suficiente: “existem milhares de solicitações adicionais para criar ou ampliar mais unidades de conservação, terras indígenas, assentamentos agrários e quilombolas. Cada vez mais, as novas áreas reivindicadas já estão ocupadas pela agricultura e até por núcleos urbanos" (MIRANDA, 2015). São destruidores de propriedades privadas (NILSON, 2015), são grupos de pessoas que estão ou deveriam estar sob uma "tutela" do Incra (NILSON, 2015). Os movimentos civis organizados são identificados como "movimentos ditos sociais" e desviadores de dinheiro público (NILSON, 2015), além de não possuírem ligação com agricultores familiares e empregados rurais, pois "se tratam de organizações clandestinas e radicais, movidas pelos princípios do stalinismo, fascismo e nazismo" (SPERAFICO, 2016). Em algumas vezes, a FPA identifica que essa demanda por terras para produção é ilegítima, pois "se integrantes dos ditos movimentos sociais realmente desejassem cultivar a terra e sustentar a família honestamente, ocupariam vagas de trabalho no campo ou buscariam o crédito fundiário, para sobreviver e crescer na atividade rural" (SPERAFICO, 2016).

As identificações mais simpáticas aos agricultores que demandam por terra identificam a política pública da reforma agrária como uma política social ou como forma de entrada para formatar produtores rurais do agronegócio (EX-ASSENTADO, 2014).

Já em relação ao órgão executor da política pública, o Instituto Nacional de Colonização e Reforma Agrária (Incra), aparece como principal incentivador de movimentos contra ruralistas e possuem trabalhos arquitetados para danificar o agronegócio (AMATO, 2012), também configuram como omissos e, essa omissão é "a principal causa do agravamento da tensão no campo" (PRODUTORES, 2013). Como apontado repetidamente que não há terras improdutivas para a reforma agrária e, para uma alternativa à desapropriação, o governo recorre a "negociatas" (GRAZIANO, 2015). Entende-se essa aquisição por preço de mercado como um "negócio de compra e venda dentro da reforma agrária, um procedimento sujeito a vastas falcatruas" com o objetivo de 
"continuar a rosca sem fim da reforma agrária, porque dela se alimentam politicamente" (GRAZIANO, 2015). Essa execução do trabalho técnico é realizada ao "bel prazer de quem ideologicamente quer conduzir o processo" (PEC, 2015). Além de destinarem "polpudos recursos públicos para financiar invasões de propriedades" e repassarem "incalculáveis somas de dinheiro para essas entidades azucrinarem quem produz alimentos no campo" (ONGS, 2015). Os órgãos públicos ainda são compostos por pessoas desonestas pois são responsáveis por "desvios e irregularidades cometidos na execução de contratos e convênios" (ONGS, 2015). A autarquia age motivada "essencialmente da lógica e da pressão de diversos grupos sociais e políticos, nacionais e internacionais" quando promovem seu trabalho "sem planejamento estratégico adequado" (MIRANDA, 2015). São inoperantes, pois permitem que assentamentos criados pela autarquia ficassem "mais de 10 anos sem que fossem concluídas obras de infraestrutura para o acesso à água" (INCRA, 2015). São responsáveis por prejudicar "os trabalhadores do campo com ações ideológicas, em muitos casos, sem o menor senso" (MERCADANTE, 2015), portanto o Incra é omisso e cúmplice do Movimento Sem Terra - MST (INCRA, 2015b). Essa ação arquitetada da autarquia foi previamente pensada e "aparelhada para atender interesses completamente diferentes daqueles que por força de lei, deveriam atender” (NILSON, 2015). Ainda assim, é “inerte”, pois não consegue avançar na reforma agrária. Essa ineficiência é a responsável por promover o crescimento da “indústria da invasão de propriedades" (NILSON, 2015). Os executores da política pública (servidores do Incra) são "guiados por ideologias extremistas" e que "há anos estão incrustados" na autarquia (NILSON, 2015).

\section{Discussão: o dito e o não dito}

A formação discursiva que acabamos de identificar nos revela o sentido que se faz nas entrelinhas das declarações e afirmações. Seus enunciados mostram-se como focalizados em decretar medidas e resoluções que favoreçam o grupo ruralistas, também se apreende dos enunciados que os grupos que venham a questionar a legitimidade dos atendidos pela Frente sejam contundentemente questionados em sua legitimidade.

Orlandi (2012) chama de mecanismo de antecipação a capacidade do sujeito de se colocar no lugar de seu interlocutor e antecipar o efeito que suas palavras teriam. Esse mecanismo permite que o sujeito a regule sua argumentação conforme o efeito que deseja produzir ao seu interlocutor. A autora compara o mecanismo de antecipação na Análise do Discurso como um jogo de xadrez no qual 
o melhor jogador, ou neste caso o melhor orador, é aquele que consegue antecipar o maior número de passos do seu adversário e se mobiliza para evitar que o outro jogador ganhe. Observa-se movimentos dos discursos da bancada ruralista sendo ajustado em relação a seus objetivos políticos.

As afirmações relacionadas à 'invasão de áreas', violência, rastro de destruição que são "financiadas com recursos públicos" (INCRA, 2015b; ONGS, 2015; SPERAFICO, 2016) a favor de uma minoria que são provenientes de uma política pública sem resultados práticos e "ligados à bandidagem" (INCRA, 2015b), são os símbolos aos quais o agronegócio denota aos movimentos sociais que demandam por terra. O Incra, como órgão responsável pela execução da reforma agrária, torna-se cúmplice deste movimento "terrorista e bandido" quando, supostamente apoia o mesmo em suas atitudes. Na disputa pelo fundo público é mais merecedora a parte que gera mais receita e é mais eficaz, portanto merece uma maior fatia do que os que são criminosos, sustentados pela máquina pública e que não possuam eficiência prática na execução da política pública. Assim, a imagem que se faz do agricultor familiar e de agricultores que demandam pela política pública da reforma agrária como pobres, sem instrução, dependentes de benefícios do governo, impelidos por ideologias e que não cultivam às terras e que, algumas vezes agem de forma criminosa não é uma imagem construída de forma espontânea.

A política pública de reforma agrária sofre ataques constantes de que "não consegue avançar”. Porém, as alternativas para se ampliar a política pública de reforma agrária são barradas pela mesma Frente Parlamentar como pode ser verificada nas matérias sobre a revisão dos índices de produtividade (GRAZIANO, 2015) e a aquisição de áreas com base no trabalho análogo à escravidão (NILSON, 2015).

Outro ponto a ser observado na releitura dessas matérias e consequente análise é a aceitação pela FPA para uma venda de propriedades rurais a empresas estrangeiras e uma constante negação para que essas terras sejam vendidas ao Estado para que ele promova uma política de redistributiva de terras através da reforma agrária. A condição de como se produz o discurso a seguir é relevante para seu processo de significação do processo discursivo realizado pela FPA: "Os principais pretextos utilizados em 2010 para justificar tal parecer foram, nas palavras da própria AGU, 'a crise de alimentos no mundo e a possibilidade de adoção, em larga escala, do biocombustível como importante fonte alternativa de energia'. Ora, desnecessário dizer que tal crise de alimentos (se é que existiu de fato) não trouxe o apocalipse previsto pela AGU e seus iluminados gurus, e que o biocombustível, em especial o nosso etanol, não se tornou uma commodity mundial, que o digam os empresários sobreviventes deste setor" (BOTELHA, 2016). Usa-se a palavra "pretexto" para explicar a argumentação da Advocacia-Geral da União (AGU) para a manutenção do território brasileiro em 
posse de pessoas e empresas nacionais. O termo "justificativa" talvez seria menos tendencioso para explicar a tomada de uma ou outra decisão. Pretexto tem definição de "motivo que declara para encobrir a verdadeira razão de algo" (PRIBERAM, 2013), também sinônimo de desculpas e subterfúgio. Já por "justificativa” entende-se uma prova que confirma a existência de um fato, subentende-se veracidade nessa proposição e ação praticada de forma justa (PRIBERAM, 2013). Assim a argumentação da AGU para não permitir a venda de propriedades rurais para pessoas e empresas estrangeiras vira um "pretexto" para uma possível intenção não revelada e utilizada para conseguir de forma escusa os objetivos pretendidos.

Observa-se também que as alegações referentes à crise de alimentos são utilizadas pela FPA em diversas ocasiões para justificar a importância do setor para o Brasil e pleitear investimentos maiores na agricultura de larga escala (AMATO, 2012; GRAZIANO, 2015; ONGS, 2015). Porém, quando se usa a mesma alegação para coibir a compra de terras brasileiras por estrangeiros observase a frase "desnecessário dizer que tal crise de alimentos (se existiu de fato) não trouxe o apocalipse previsto pela AGU e seus iluminados gurus" (BOTELHA, 2016). Assim, as mesmas argumentações são utilizadas dependendo da sua conveniência e, como percebemos aqui, elas podem cair em contradição.

Botelha (2016) ainda conclui em sua argumentação que "felizmente, os ventos mudam e o momento de crise atual exige menos ideologia e mais inteligência e pragmatismo para defender os reais interesses nacionais". Observa-se que o artigo foi publicado em 22 de junho de 2016, meses antes da conclusão do processo que iniciou em dezembro de 2015 e que culminou na cassação do mandato de Dilma Rousseff como presidenta do país em 31 agosto de 2016. Essa informação está subentendida na expressão "os ventos mudam". Ainda verificando a mesma frase, usa-se a palavra "ideologia", que em seu conceito sociológico pode ser caracterizada como um sistema de ideias que são sustentadas por um grupo social e que refletem os interesses desse grupo. A questão ideológica, na fala acima, assume uma conotação ruim quando a ideologia é contrária à dos grandes produtores e ruralistas defendidos pela Frente Parlamentar de Agropecuária. A ideologia defendida pelo grupo social ligado ao agronegócio, defende o liberalismo econômico, o livre mercado, porém, ao contrário da outra, essa ideologia não deve ser diminuída. Desta forma, o pedido por "menos ideologia" se consolida e "menos ideologia contrária a qual eu me identifico". Ao final, conclui-se que a este novo posicionamento menos ideológico, mais inteligente e pragmático seria em defesa dos "reais interesses nacionais". Esses "interesses reais da nação" seria o de permitir o uso do seu território por empresas e pessoas não brasileiras e excluir o próprio gerenciamento de território nacional para seu uso das pessoas e empresas nacionais? Aqui denota-se uma confusão sobre o significado da expressão "reais 
interesses nacionais", a defesa dos interesses da nação diferencia-se da defesa de interesses nacionais específicos de um determinado grupo. Essa defesa de interesses nacionais não está em consonância com os interesses da maioria da população. Vê-se por hora que a diminuição da ideologia e mais trabalho prático poderia trazer bons frutos ao "real interesse nacional", porém aprofundando-se no texto proferido, a intenção é a diminuição da ideologia que é contrária à venda de terras para empresas ou pessoas não-brasileiras. Assim a FPA usa de expressões nacionalistas de defesa dos interesses que ela coloca como legítimos e verdadeiros interesses do país, mas são, de fato, interesses de um grupo econômico.

Em 2015 o Incra tenta atuar na desapropriação de áreas que possuam infrações em leis trabalhistas (MERCADANTE, 2015). Nesta ocasião o texto destaca a "violação dos princípios constitucionais" sobre uma Instrução Normativa (IN) no 83/2015 do Incra que estabelece que "os imóveis constantes no cadastro de empregadores que tenham mantido trabalhadores em condições análogas à de escravo de que trata a Portaria Interministerial MTE/SEDH no 2o, de 31 março de 2015”. A Frente Parlamentar da Agropecuária (FPA) queixa-se de medidas que estariam sendo adotadas por "subalternos". Pede-se a revogação da IN, pois alega que a medida é "inconstitucional" e "piora a situação de insegurança jurídica no campo". "A FPA quer colaborar para que o Brasil saia da crise, mas não podemos aceitar que gente do governo prejudique os trabalhadores do campo com ações ideológicas, em muitos casos, sem o menor senso. Com mais esta norma, estão querendo inaugurar uma nova modalidade de promoção da Reforma Agrária às custas do produtor rural, violando princípios constitucionais" (MERCADANTE, 2015). Observa-se aqui que por "insegurança jurídica" entende-se um avanço sobre a propriedade privada e não sobre as questões relativas ao direito trabalhista no campo. Também é evocado aqui os "princípios constitucionais", porém orientado apenas sobre a propriedade privada. Os demais princípios constitucionais voltados à questão trabalhista, social ou do próprio cumprimento da função social da propriedade - também inserida na Constituição - são ignorados.

Nesta análise de discurso, observa-se as diferentes formas de não-dizer. Vê-se que, ao longo dos dizeres sobre os princípios constitucionais, há toda uma margem de não-ditos que também significam (ORLANDI, 2012). Assim, observa-se que, o que não é dito constitui sentido e corrobora com a argumentação sobre o que é dito. Nessa questão, destaca-se apenas "os princípios constitucionais" sobre a questão da propriedade privada e evoca-se a "segurança jurídica" para que essa mesma propriedade privada seja mantida. O silenciamento sobre as questões - também constitucionais - trabalhistas e de promoção da reforma agrária fazem igualmente sentido no texto quanto o de destacar apenas as questões do direito de propriedade. Silenciar os deveres que um 
proprietário de terras possui no cumprimento da função social da propriedade conforme o estabelecido pelo Art. 186 da Constituição Federal de 1988 é dar voz ao conceito tradicional Direito de Propriedade como um fim em si: tem-se. Omite-se a conceituação de propriedade como território e como um recurso econômico que é escasso e limitado e que legalmente possui amparo constitucional para a obediência da função social. O silenciamento destes conceitos traz também significação para este texto.

Essa possível inversão de relações de trabalho no campo que a política pública de reforma agrária influencia é outro ponto que merece destaque na análise. Receber e cultivar sua própria terra e ser um protagonista da sua história de crescimento parece algo questionável do ponto de vista dos ruralistas. "Se integrantes dos ditos movimentos sociais realmente desejassem cultivar a terra e sustentar a família honestamente, ocupariam vagas de trabalho no campo" (SPERAFICO, 2016). Assim, almejar ter sua própria terra é questionável do ponto de vista da honradez. Sob estes preceitos morais válidos para os ruralistas almejar ter sua própria terra é repreensível moralmente.

O órgão executor da política pública é mostrado como aparelhado (NILSON, 2015) quando quer denotar que os funcionários que ali estão colocados se usam da sua competência funcional para beneficiar um movimento social específico e, ou, atacar os proprietários de terras. A conotação "aparelhamento" do órgão implica em um controle por grupos ideologizados politicamente. "Aparelho", durante a ditadura militar no Brasil era o termo que se referia a um local usado por uma organização política clandestina - normalmente contra o regime ditatorial - servindo também para a realização de reuniões, guarda de material de propaganda, dinheiro, armas, etc. Desta forma, quando se coloca o Incra como órgão "aparelhado", denota-se um órgão utilizado para fins não republicanos e em benefício de apenas um grupo.

\section{Considerações finais}

A disputa entre agronegócio e reforma agrária (e estende-se ao modelo de agricultura familiar) se dá em plano mais amplo: pelo fundo público e pelo direcionamento de políticas públicas.

A execução da política pública de reforma agrária faz com que o Estado se volte à sua população e ao bem-estar de seu povo. A decisão de não fazer a reforma agrária e deixar que poucas pessoas usem a parte do território para um uso exclusivo - deixando a cargo do mercado sua regulamentação - o Estado, portanto, volta suas ações em benefício do mercado. A escolha do modelo do Estado - se voltado ao bem-estar da sua população ou voltado ao equilíbrio da balança comercial 
de mercado - somado a como este Estado administrará a ocupação do seu território e de como gastará seu dinheiro é o campo de contenda. Para além da agricultura, o certame se extrapola para um modelo de Estado. Há uma escolha feita pelo Estado e seus governos no momento de impor uma pauta de desenvolvimento rural voltado à mecanização do campo e desconstruir os saberes tradicionais e locais, em impor uma agenda econômica sobre agendas ambientais e sociais; uma pauta de superavit da balança comercial sobre o bem-estar da população e a pauta tecnológica de agricultura intensiva sobre a segurança e soberania alimentar.

Essa política pública vive uma disputa que pode ser identificada pelo âmbito discursivo e tem rebatimento na aplicação do fundo público. A política pública da reforma agrária recebe ataques discursivos do agronegócio, mas esse antagonismo e disputas não se dão necessariamente no âmbito pessoal ou mesmo regional. Há dois modelos de agricultura e um único Estado e um único fundo público. Essa concorrência almeja ganhos mais amplos como uma maior fatia ou a exclusividade do fundo público e o direcionamento de políticas públicas.

Importante observar que essa disputa discursiva não se dá em proporções igualitárias de forças. A organização dentro do Estado pela Frente Parlamentar de Agricultura é mais relevante e possui maior representatividade no parlamento brasileiro e, consequentemente, nas pautas públicas do que a posição dos agricultores familiares.

O resgate desses textos pode mostrar a força nas conduções políticas do país, seja por políticas públicas voltadas ao agronegócio e mesmo por looby a nomes que conduziriam a política pública. Um próximo movimento identificado pelos textos da FPA é o de cooptação de setores da Agricultura Familiar para o agronegócio, tornando-se um híbrido. A política de reforma agrária ou outra de fomento à agricultura familiar seria uma política pública de entrada ao que culminaria em grandes áreas e industrialização do agronegócio. E, nesse movimento que discursivamente se torna previsível se formata o agrário para o agrícola, desvinculando o problema da pobreza e conflito no campo com o avanço conservador e moderno da agricultura e, ao limitar a obtenção de propriedades para a reforma agrária somente no âmbito da improdutividade, é arquitetado também um modelo de Estado sem a superação do modelo econômico atual e, portanto, mantendo as forças que estruturam o agronegócio.

\section{Referências}

AGROPECUÁRIA pode ficar com pelo menos $20 \%$ do crédito subsidiado do BNDES. Agência FPA. 11 jun. 2015. 
AMATO, R. Os desafios do agronegócio. Agência FPA. 06 dez. 2012.

AZAMBUJA, D. Teoria geral do Estado. Globo Livros, 2008.

BANCADA ruralista oficializa apoio a Rodrigo Maia. Agência FPA. 01 fev. 2017

BOTELHA, W. G. Investimentos estrangeiros em terras brasileiras: País merece e precisa. Agência FPA. 22 jun. 2016

BRASIL. Constituição (1988). Constituição da República Federativa do Brasil. Brasília, DF: Senado Federal: Centro Gráfico, 1988.

BRASIL. II Plano Nacional de Reforma Agrária - Paz, produção e Qualidade de vida no Meio Rural. Brasília, 2003. Disponível em:

<http://www.incra.gov.br/media/servicos/publicacao/pnra/II_PNRA.pdf $>$ Acesso em: 18 fevereiro. 2018.

BUAINAIN, A. M. et al. Sete teses sobre o mundo rural brasileiro. Revista de política agrícola, v. 22, n. 2, p. 105-121, 2013.

PRIBERAM, Dicionário. Disponível em: http://www. priberam. pt/dlpo. Acesso em, 19 jul 2019, v. 28, 2013.

EM fórum, lideranças do agro cobram mais segurança jurídica no campo. Agência FPA. 21 set. 2015.

EX-ASSENTADO, ministro da Agricultura enumera ações a serem executadas. Agência FPA. 18 mar. 2014.

GRAZIANO, X. Produtividade e ideologia no campo. Agência FPA. 02 fev. 2015.

IBGE. Censo Agropecuário 1920/2006. Até 1996 dados extraídos de: Estatísticas do Século XX. Rio de Janeiro: IBGE, 2007.

INCRA e MDA serão fiscalizados pela Comissão de Agricultura da Câmara dos Deputados. Agência FPA. 13 ago. 2015.

INCRA é omisso e cúmplice do MST, diz Nilson Leitão. Agência FPA. 09 out. 2015b.

LEITE, S. et al. Impactos dos assentamentos: um estudo sobre o meio rural brasileiro. Unesp, 2004.

MACHADO, I. L. Análise do Discurso e seus múltiplos sujeitos. In: MACHADO, I.

L.; CRUZ, A. R.; LYSARDO-DIAS, D. (Orgs.). Teorias e Práticas 
Discursivas. Estudos em Análise do Discurso. Belo Horizonte: Carol Borges/NAD-FALEUFMG, 1998. p. 111-121.

MERCADANTE admite ações "à revelia" do governo e diz que vai suspender IN do Incra. Agência FPA. 21 ago. 2015.

MIRANDA, T.; ARAÚJO, N. Frente Agropecuária pede a Temer suspensão da demarcação de terras indígenas. Agência FPA. 17 mai. 2013.

MINISTRO admite necessidade de mudar processo de demarcação de áreas indígenas. Agência FPA. 21 nov. 2013.

NILSON Leitão é indicado para CPI da Funai e do Incra. Agência FPA. 06 nov. 2015.

ONGS que azucrinam agricultores serão investigadas por CPI. Agência FPA. 01 abr. 2015.

ORLANDI, E. P. Análise de discurso: princípios \& procedimentos. Pontes, 2012.

PEC polêmica sobre demarcação de terras indígenas pode voltar a análise na Câmara. Agência FPA. 02 fev. 2015.

PRODUTORES culpam governo pelo agravamento de conflitos com indígenas. Agência FPA. 31 out. 2013.

SPERAFICO, D. A realidade do campo e a inviabilidade da reforma agrária. Agência FPA. 08 abr. 2016.

TEMER virá à reunião-almoço da FPA na próxima terça-feira. Agência FPA. 05 jul. 2016.

TERRAS indígenas. Senado aprova indenização para legítimos donos. Agência FPA. 26 mar. 2015.

Artigo recebido em 05/12/2019. Aceito para publicação em 26/12/2019. 